Journal of Engineering and Applied Sciences 14 (3): 905-912, 2019

ISSN: 1816-949X

(C) Medwell Journals, 2019

\title{
A New Type of Strongly Faint Continuous Mappings and Their Applications in Topological Spaces
}

\author{
Alaa M.F. Al. Jumaili, Alaa A. Auad and Majid Mohammed Abed \\ Department of Mathematics, College of Education for Pure Science, University of Anbar, \\ Ramadi, Iraq
}

\begin{abstract}
In the present study, we introduce and investigate a new strong form of faint continuity called strongly faint $\delta$ - $\beta$-continuous mappings by using the concept of $\delta$ - $\beta$-open sets. Relationships among strongly faint $\delta$ - $\beta$-continuous mappings and $\delta$ - $\beta$-connected Spaces, $\delta$ - $\beta$-normal spaces and $\delta$ - $\beta$-ompact spaces are investigated. Several characterizations and interesting properties concerning strongly faint $\delta$ - $\beta$-continuous mappings are obtained. Also, the relationships between strongly faint $\delta$ - $\beta$-ontinuous mappings and graphs are investigated. Furthermore, the relationships between strongly faint $\delta$ - $\beta$-continuous mappings and other of well-known types of strongly faint continuous mappings are also given.
\end{abstract}

Key words: $\delta$ - $\beta$-open sets, $\delta$ - $\beta$-regular space, strongly $\delta$ - $\beta$-continuous, strongly faint $\delta$ - $\beta$-continuous, mappings, investigated

\section{INTRODUCTION}

The notion of continuity is an important concept in general topology as well as all branches of mathematics of course its weak forms and strong forms of continuity are important, too. Recent progress in the study of characterizations and generalizations of continuity, compactness, connectedness, separation axioms etc. has been done by means of several generalized closed sets. Generalized closed sets are now well-known important notions in topology and its applications. Many topologists are focusing their research on these topics and this amounted to many important and useful results. By Levine (1970) introduced the first step of generalizing closed set. As a generalization of closed sets, $\mathrm{e}^{*}$-Closed sets and the related sets were introduced and studied by Ekici (2008a-c, 2009) and Hatir and Noiri (2006). Nasef and Noiri (1996) introduced three classes of strong forms of faintly continuity namely: strongly faint semicontinuity, strongly faint precontinuity and strongly faint $\beta$ continuity. Nasef (2009) defined strong forms of faint continuity under the terminologies strongly faint $\alpha$ continuity and strongly faint $\gamma$-continuity, Recently, Farhan and Yang (2015) introduced and investigated a new class of strong continuous functions called strongly $\theta-\delta$ - $\beta$-continuous functions. As well, Caldas and Jafari (2011) introduced a new class of mappings, called strongly faint e-Continuous mappings, the purpose of the present this study is to introduce and investigate another new strong form of faint continuity namely strongly faint $\delta$ - $\beta$-continuous mappings. $S$ everal characterizations and basic properties concerning strongly faint $\delta$ - $\beta$-continuous mappings are obtained. Moreover, relationships between strongly faint $\delta$ - $\beta$ continuous mappings and graphs are discussed.

\section{MATERIALS AND METHODS}

Throughout, the present study, $(\mathrm{X}, \mathrm{T})$ and $\left(\mathrm{Y}, \mathrm{T}^{*}\right)$ (or simply $\mathrm{X}$ and $\mathrm{Y}$ ) mean topological spaces on which no separation axioms are assumed unless explicitly stated. For any subset $\mathrm{A}$ of $\mathrm{X}$, the closure and interior of $\mathrm{A}$ are denoted by $\mathrm{Cl}(\mathrm{A})$ and $\operatorname{Int}(\mathrm{A})$, respectively. We recall the following definitions which will be used often throughout this study.

Let X be a topological space. A subset A of X is called $\alpha$-open (Njastad, 1965) (resp. semi-open (Levine, 1963), pre-open (Mashhour et al., 1982), $\beta$-open (El-Monsef et al., 1983), $\gamma$-open (El-Atik, 1997) $\delta$-pre-open (Raychaudhuri and Mukherjee, 1993) if A $\subset \operatorname{Int}(\mathrm{Cl}(\operatorname{Int}(\mathrm{A})$ (resp. $\mathrm{A} \subset \mathrm{Cl}(\operatorname{Int}(\mathrm{A})), \mathrm{A} \subset \operatorname{Int}(\mathrm{Cl}(\mathrm{A})), \mathrm{A} \subset \mathrm{Cl}(\operatorname{Int}(\mathrm{Cl}(\mathrm{A})))$, $\left.\mathrm{A} \subset \operatorname{Int}(\mathrm{Cl}(\mathrm{A})) \cup \mathrm{Cl}(\operatorname{Int}(\mathrm{A})), \mathrm{A} \subset \operatorname{Int}\left(\mathrm{Cl}_{8}(\mathrm{~A})\right)\right)$. The family of all $\alpha$-open (resp., semi-open, preopen, $\beta$-open, $\gamma$-open) sets in $\mathrm{X}$ are denoted by $\alpha \Sigma(\mathrm{X}, \mathrm{T})$ (resp. $\mathrm{S} \Sigma(\mathrm{X}, \mathrm{T}), \mathrm{P} \Sigma(\mathrm{X}$, $\mathrm{T}), \beta \Sigma(\mathrm{X}, \mathrm{T}), \mathrm{B} \Sigma(\mathrm{X}, \mathrm{T}))$.

A point $x \in X$ is called a $\theta$-cluster (Velicko, 1968) (resp. $\delta$-cluster (Velicko, 1968)) point of A if $\mathrm{Cl}(\mathrm{V}) \cap \mathrm{A} \neq \varnothing$ (resp. $\operatorname{Int}(\mathrm{C} 1(\mathrm{~V})) \cap \mathrm{A} \neq \varnothing)$ for every open set $\mathrm{V}$ of $\mathrm{X}$ containing $\mathrm{X}$.

Corresponding Author: Alaa M.F. Al. Jumaili, Department of Mathematics, College of Education for Pure Science, University of Anbar, Ramadi, Iraq 
The set of all $\theta$-cluster (resp. $\delta$-cluster) points of $\mathrm{A}$ is called the $\theta$-closure (resp. $\delta$-closure) of $\mathrm{A}$ and is denoted by $\mathrm{Cl}_{\theta}(\mathrm{A})\left(\operatorname{resp} . \mathrm{Cl}_{8}(\mathrm{~A})\right)$. If $\mathrm{A}=\mathrm{Cl}_{\theta}(\mathrm{A})\left(\operatorname{resp} . \mathrm{A}=\mathrm{Cl}_{8}(\mathrm{~A})\right)$, then $\mathrm{A}$ is said to be $\theta$-closed (resp. $\delta$-closed). The complement of a $\theta$-closed (resp. $\delta$-closed) set is said to be $\theta$-open (Velicko, 1968) (resp. $\delta$-open (Veli icko, 1968)). The union of all $\theta$-open sets contained in a subset $\mathrm{A}$ is called the $\theta$-interior of $A$ and is denoted by $\operatorname{Int}_{\theta}(A)$. It follows from (Velicko, 1968) that the collection of $\theta$-open sets in a topological space $\left(\mathrm{X}, \mathrm{T}\right.$ ) forms a topology $\mathrm{T}_{\theta}$ on $\mathrm{X}$ (Long and $\mathrm{H}$ errington, 1982). The family of all $\theta$-open (resp. $\theta$-closed) subsets of $\mathrm{X}$ is denoted by $\theta \Sigma(\mathrm{X}, \mathrm{T})$ (resp. $\theta \mathrm{C}(\mathrm{X}, \mathrm{T})$ ). The family of all $\theta$-open (resp. $\theta$-closed) subsets of $\mathrm{X}$ containing a point $\mathrm{x} \in \mathrm{X}$ is denoted by $\theta \Sigma(\mathrm{X}, \mathrm{x})($ resp. $\theta \mathrm{C}(\mathrm{X}, \mathrm{x}))$.

A subset $\mathrm{A}$ of a space $\mathrm{X}$ is called $\delta$ - $\beta$-open (Hatir and Noiri, 2009) or e ${ }^{*}$-open (Ekici, 2008a-c), if $\mathrm{A} \subset \mathrm{Cl}(\operatorname{Int}(\boldsymbol{\delta}$-Cl (A)), the complement of a $\delta$ - $\beta$-open set is called $\delta$ - $\beta$-closed. The intersection of all $\delta$ - $\beta$-closed sets containing A is called the $\delta$ - $\beta$-closure of A (Hatir and Noiri, 2006) and is denoted by $\delta-\beta-C l(A)$. The union of all $\delta$ - $\beta$-open sets of $\mathrm{X}$ contained in $\mathrm{A}$ is called the $\delta$ - $\beta$-interior (Hatir and Noiri, 2006) of $A$ and is denoted by $\delta$ - $\beta$-Int(A). The family of all $\delta$ - $\beta$-open (resp. $\delta$ $\beta$-closed) subsets of $X$ containing a point $\mathrm{x} \in \mathrm{X}$ is denoted by $\delta-\beta \Sigma(X, x)$ (resp. $\delta-\beta C(X, X)$ ), the family of all $\delta-\beta$-open (resp. $\delta$ - $\beta$-closed) sets in X are denoted by $\delta-\beta \Sigma(X, T)$ $($ resp. $\delta-\beta C(\mathrm{X}, \mathrm{T})$ ).

Remark 2.1: Since, the notion of $\delta$ - $\beta$-open sets and the notion of $\mathrm{e}^{*}$-open sets are same, we will use the term $\delta$ - $\beta$-open sets instead of $\mathrm{e}^{*}$-open sets.

Lemma 2.2: Ekici (2008a-c) and Hatir and Noiri (2009) the following properties hold for the $\delta$ - $\beta$-closure of a subset A of a space $X$ :

- The Arbitrary union (intersection) of $\delta$ - $\beta$-open (resp. $\delta$ - $\beta$-closed) sets in X is $\delta$ - $\beta$-open (resp. $\delta$ - $\beta$-closed) set

- $\quad \mathrm{A}$ is $\delta-\beta$-closed in $\mathrm{X} \Leftrightarrow \mathrm{A}=\delta-\beta-\mathrm{Cl}(\mathrm{A})$

- $\delta-\beta-C l(A)$ is $\delta$ - $\beta$-closed

- $\quad \delta-\beta-\mathrm{Cl}(\mathrm{A}) \subset \delta-\beta-\mathrm{Cl}(\mathrm{B}) \forall \mathrm{A} \subset \mathrm{B} \subset \mathrm{X}$

- $\delta-\beta-\mathrm{Cl}(\delta-\beta-\mathrm{Cl}(\mathrm{A}))=\delta-\beta-\mathrm{Cl}(\mathrm{A})$

- $\mathrm{x} \in \delta$ - $\beta$-Cl(A) if $A \cap U \neq \varnothing \forall \delta$ - $\beta$-open set $U$ containing $x$

Remark 2.3: Ekici (2008a-c) shows that the notions of e-open set and b-open set and the notions of e-open set and $\beta$-open set and the notions of e-open set and semi-open set are independent as shown in example 2.6 (Ekici, 2008a-c) (Fig. 1).

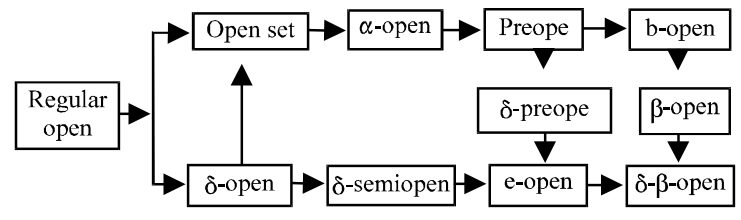

Fig. 1: The relationships among some well-known generalized open sets in topological spaces

Remark 2.4: We have the following diagram in which the converses of implications need not be true, see the examples by Hatir and Noiri (2009) and Ekici $(2008 \mathrm{a}-\mathrm{c})$.

Definition 2.5: A mapping $f:(X, T) \rightarrow\left(Y, T^{*}\right)$ is said to be:

- Strongly $\theta$-Continuous (Noiri, 1980 ), if $\mathrm{f}^{-1}(\mathrm{~V})$ is $\theta$ open in $\mathrm{X}$ for every open set $\mathrm{V}$ of $\mathrm{Y}$

- Quasi $\theta$-continuous (Jafari, 1998) if $\mathrm{f}^{1}(\mathrm{~V})$ is $\theta$-open in $\mathrm{X}$ for every $\theta$-open set $\mathrm{V}$ of $\mathrm{Y}$

- $\delta$ - $\beta$-Continuous (Ekici, 2008a-c; Hatir and Noiri, 2006) if $\mathrm{f}^{-1}(\mathrm{~V})$ is $\delta$ - $\beta$-open in $\mathrm{X}$ for every open set $\mathrm{V}$ of $\mathrm{Y}$

- $\delta$ - $\beta$-Irresolute (Ekici, 2007a, b) if $\mathrm{f}^{-1}(\mathrm{~V})$ is $\delta$ - $\beta$-open in $\mathrm{X}$ for every $\delta$ - $\beta$-open set $\mathrm{V}$ of $\mathrm{Y}$

\section{RESULTS AND DISCUSSION}

Characterizations of strongly faint $\boldsymbol{\delta}$ - $\boldsymbol{\beta}$-continuous mappings: In this study, we obtain several characterizations and fundamental properties concerning strongly faint $\delta$ - $\beta$-Continuous mappings.

Definition 3.1: A mapping $f:(X, T) \rightarrow\left(Y, T^{*}\right)$ is said to be: strongly faint $\delta-\beta$-continuous if for each $\mathrm{x} \in \mathrm{X}$ and each $\delta$ - $\beta$-open set $V$ of $Y$ Containing $f(x)$, there exists a $\theta$-open set $U$ of $X$ containing $x$ such that $f(U) \subset V$. Strongly $\delta$ - $\beta$-continuous if $\mathrm{f}^{-1}(\mathrm{~V})$ is open in $\mathrm{X}$ for every $\delta$ - $\beta$-open set $V$ of $Y$.

Theorem 3.2: For a mapping $f:(X, T) \rightarrow\left(Y, T^{*}\right)$, the following statements are equivalent:

- $\quad \mathrm{f}$ is strongly faint $\delta$ - $\beta$-continuous

- $\mathrm{f}:\left(\mathrm{X}, \mathrm{T}_{\mathrm{e}}\right) \rightarrow\left(\mathrm{Y}, \mathrm{T}^{*}\right)$ is strongly $\delta$ - $\beta$-continuous

- $\mathrm{f}^{1}(\mathrm{~V})$ is $\theta$-open in $X$ for every $\delta$ - $\beta$-open set $V$ of $Y$

- $\mathrm{f}^{-1}(\mathrm{~F})$ is $\theta$-closed in $\mathrm{X}$ for every $\delta$ - $\beta$-closed subset $F$ of $Y$

Proof: (a) $\Rightarrow$ (b) and (b) $\Rightarrow$ (a) is obvious thus omitted.

(a) $\Rightarrow$ (c): Let, $V$ be an $\delta$ - $\beta$-open set of $Y$ and $x \in f^{-1}(V)$. Since, $\mathrm{f}(\mathrm{x}) \epsilon \mathrm{V}$ and $\mathrm{f}$ is strongly faint $\delta$ - $\beta$-continuous, there exists 
a $\theta$-open set $U$ of $X$ containing $x$ such that $f(U) \subset V$. It follows that $\mathrm{x} \in U \subset \mathrm{f}^{-1}(\mathrm{~V})$. Hence, $\mathrm{f}^{1}(\mathrm{~V})$ is $\theta$-open in $\mathrm{X}$.

(c) $\Rightarrow$ (a): Let $x \in X$ and $V$ be an $\delta$ - $\beta$-open set of $Y$ containing $\mathrm{f}(\mathrm{x})$. By $(\mathrm{c}), \mathrm{f}^{-1}(\mathrm{~V})$ is a $\theta$-open set containing $\mathrm{x}$. Take $U=f^{1}(V)$. Then, $f(U) \subset V$. This shows that $f$ is strongly faint $\delta$ - $\beta$-continuous.

(c) $\Rightarrow$ (d): Let $V$ be any $\delta$ - $\beta$-closed set of $Y$. Since, $Y \backslash V$ is an $\delta$ - $\beta$-open set, by (c), we have $\mathrm{f}^{1}(\mathrm{Y} \backslash \mathrm{V})=\mathrm{X} \backslash \mathrm{f}^{-1}(\mathrm{~V})$ is $\theta$-open. This shows that $\mathrm{f}^{1}(\mathrm{~V})$ is $\theta$-closed in $\mathrm{X}$.

(d) $\Rightarrow$ (c): Let $V$ be an $\delta$ - $\beta$-open set of $Y$. Then, $Y \backslash V$ is $\delta$ - $\beta$-closed in $Y$. By $(d), f^{-1}(Y \backslash V)=X \backslash f^{-1}(V)$ is $\theta$-closed and thus $\mathrm{f}^{-1}(\mathrm{~V})$ is $\theta$-open.

Theorem 3.3: If a mapping $\mathrm{f}:(\mathrm{X}, \mathrm{T}) \rightarrow\left(\mathrm{Y}, \mathrm{T}^{*}\right)$ is strongly faint $\delta$ - $\beta$-continuous mapping, then it is strongly $\delta$ - $\beta$-continuous.

Proof: It is straightforward thus omitted. If $(\mathrm{X}, \mathrm{T})$ is a regular space, we have $T=T_{\theta}$ and the next theorem follows immediately.

Theorem 3.4: If $(\mathrm{X}, \mathrm{T})$ is a regular space, Then the following properties are equivalent for a mapping $\mathrm{f}$ : $(\mathrm{X}, \mathrm{T}) \rightarrow\left(\mathrm{Y}, \mathrm{T}^{*}\right)$ :

- $\mathrm{f}$ is strongly $\delta$ - $\beta$-continuous.

- $\mathrm{f}$ is strongly faint $\delta$ - $\beta$-continuous

Definition 3.5: A topological space $\left(Y, T^{*}\right)$ is said to be $\mathrm{T}_{\delta \text { - } \beta}$-space if every $\delta$ - $\beta$-open subset of $\left(Y, T^{*}\right)$ is open. Recall that a topological space $\left(Y, T^{*}\right)$ is said to be a $\mathrm{T}_{e}$-space (Caldas and Jafari, 2011) if every e-open subset of $Y, T^{*}$ is open.

Definition 3.6: A $\theta$-frontier (Jafari, 1998) of a subset $A$ of $\mathrm{X}, \mathrm{T}$ is $\mathrm{Fr}_{\theta}(\mathrm{A})=\mathrm{Cl}_{\theta}(\mathrm{A}) \cap \mathrm{Cl}_{\theta}(\mathrm{X} \backslash \mathrm{A})$.

Theorem 3.7: Let $(X, T)$ be a regular space. Then, the set of all points $\mathrm{x} \in \mathrm{X}$ in which a mapping $\mathrm{f}:(\mathrm{X}, \mathrm{T}) \rightarrow\left(\mathrm{Y}, \mathrm{T}^{*}\right)$ is not strongly faint $\delta$ - $\beta$-continuous at $\mathrm{x}$ is identical with the union of the $\theta$-frontier of the inverse images of $\delta$ - $\beta$-open subsets of $Y$ containing $f(x)$.

Proof; Necessity: Suppose that $f$ is not strongly faint $\delta$ - $\beta$-continuous at $\mathrm{x} \in \mathrm{X}$. Then, there exists an $\delta$ - $\beta$-open set $V$ of $Y$ containing $f(x)$ such that $f(U) \nsubseteq V$ for each $U \epsilon T_{\theta}$ containing $\mathrm{x}$. Hence, we have $\mathrm{U} \cap\left(\mathrm{X} \backslash \mathrm{f}^{-1}(\mathrm{~V})\right) \neq \varnothing$ for each $\mathrm{U}_{\epsilon} \mathrm{T}_{\theta}$ containing $\mathrm{x}$. Since, $\mathrm{X}$ is regular, it follows that $\mathrm{x} \epsilon \mathrm{Cl}_{\theta}\left(\mathrm{X} \backslash \mathrm{f}^{-1}(\mathrm{~V})\right)$. On the other hand we have that, $\mathrm{x} \epsilon$ $\mathrm{f}^{1}(\mathrm{~V}) \subset \mathrm{Cl}_{\theta}\left(\mathrm{f}^{1}(\mathrm{~V})\right)$. This means that $\mathrm{x} \in \mathrm{Fr}_{\theta}\left(\mathrm{f}^{1}(\mathrm{~V})\right)$.
(Sufficiency): Suppose that $x \in \operatorname{Fr}_{\theta}\left(f^{-1}(V)\right)$ for some $V \epsilon \delta$ $\beta \Sigma(\mathrm{Y}, \mathrm{f}(\mathrm{x}))$. Now, we assume that $\mathrm{f}$ is strongly faint $\delta-\beta$ continuous at $\mathrm{x} \in \mathrm{X}$. Then, there exists $\mathrm{U}_{\epsilon} \mathrm{T}_{\theta}$ containing $\mathrm{x}$ such that $f(U) \subset V$. Therefore, we have $U \subset f^{-1}(V)$ and hence, $x \in \operatorname{Int}_{\theta}\left(\mathrm{f}^{1}(\mathrm{~V})\right) \subset \mathrm{XVFr}_{\theta}\left(\mathrm{f}^{1}(\mathrm{~V})\right)$. This is a contradiction. This means that $\mathrm{f}$ is not strongly faint $\delta$ - $\beta$-continuous.

Definition 3.8: A topological space (X, T) is said to be; $\delta$ - $\beta$-Connected (Ekici, 2008a-c; Hatir and Noiri, 2009) (resp. 8 -connected (Jafari, 1998)) if X cannot be written as the union of two nonempty disjoint $\delta$ - $\beta$-open (resp. $\theta$ open) sets. A subset $M$ of a space $(X, T)$ is said to be $\delta$ - $\beta$-compact (Ekici, 2007a, b; 2008a-c) (resp. $\theta$ compact (Jafari, 1998)) relative to $\mathrm{X}, \mathrm{T}$ if for every cover of M by $\delta$ - $\beta$-open (resp. $\theta$-open) sets has a finite subcover. A topological space $(\mathrm{X}, \mathrm{T})$ is $\delta$ - $\beta$-compact (Ekici, 2007a, b; 2008a-c) (resp. 8 -compact (Jafari, 1998)) if the set $\mathrm{X}$ is $\delta$ - $\beta$-compact (resp. $\theta$-compact) relative to (X, T). It should be mentioned that $\theta$-connected is equivalent with connected (Jafari, 1998).

Theorem 3.9: Let $f:(X, T) \rightarrow\left(Y, T^{*}\right)$ be a strongly faint $\delta$ - $\beta$-continuous surjection mapping and $(\mathrm{X}, \mathrm{T})$ is a $\theta$-connected space, then $Y$ is a $\delta$ - $\beta$-connected space.

Proof: Suppose that $\left(Y, T^{*}\right)$ is not $\delta$ - $\beta$-connected. Then there exist non-empty $\delta$ - $\beta$-open sets $V_{1}$ and $V_{2}$ of $Y$ such that $V_{1} \cap V_{2}=\varnothing$ and $V_{1} \cap V_{2}=Y$. Hence, we have $\mathrm{f}^{-1}\left(\mathrm{~V}_{1}\right) \cap \mathrm{f}^{-1}\left(\mathrm{~V}_{2}\right)=\varnothing$ and $\mathrm{f}^{-1}\left(\mathrm{~V}_{1}\right) \cup \mathrm{f}^{-1}\left(\mathrm{~V}_{2}\right)=\mathrm{X}$. Since, $\mathrm{f}$ is surjective, $\mathrm{f}^{-1}\left(\mathrm{~V}_{1}\right)$ and $\mathrm{f}^{1}\left(\mathrm{~V}_{2}\right)$ are non-empty subsets of $\mathrm{X}$. Since, $f$ is strongly faint $\delta$ - $\beta$-continuous, then $\mathrm{f}^{1}\left(\mathrm{~V}_{1}\right)$ and $\mathrm{f}^{-1}\left(\mathrm{~V}_{2}\right)$ are $\theta$-open sets of $\mathrm{X}$. Therefore, we have $(\mathrm{X}, \mathrm{T})$ is not $\theta$-connected. This is a contradiction and hence $\left(\mathrm{Y}, \mathrm{T}^{*}\right)$ is $\delta$ - $\beta$-connected.

Theorem 3.10: Let $f:(X, T) \rightarrow\left(Y, T^{*}\right)$ be a strongly faint $\delta$ - $\beta$-continuous, then $f(M)$ is $\delta$ - $\beta$-compact relative to $\left(\mathrm{Y}, \mathrm{T}^{*}\right)$ for each subset $\mathrm{M}$ which is $\theta$-compact relative to $\mathrm{X}$.

Proof: Let $\left\{\mathrm{V}_{\lambda}: \lambda \in \Delta\right\}$ be any cover of $\mathrm{f}(\mathrm{M})$ by $\delta$ - $\beta$-open sets. For each $x \in M$, there exists $\lambda_{\mathrm{z}} \in \Delta$ such that $\mathrm{f}(\mathrm{x}) \mathrm{V}_{\lambda_{\mathrm{x}}}$. Since, $\mathrm{f}$ is strongly faint $\delta$ - $\beta$-continuous, there exists $\mathrm{U}_{\mathrm{z}} \in \mathrm{T}_{\theta}$ containing $\mathrm{x}$ such that $\mathrm{f}\left(\mathrm{U}_{\mathrm{z}}\right) \subset \mathrm{V}_{\lambda \mathrm{x}}$. The family $\left\{\mathrm{U}_{\mathrm{z}}\right.$ : $x \in M\}$ is a cover of $M$ by $\theta$-open sets of $X, T$. Since, $M$ is $\theta$-compact relative to $(X, T)$, there exists a finite subset $M_{0}$ of $\mathrm{M}$ such that $\mathrm{M} \subset \cup\left\{\mathrm{U}_{\mathrm{z}}: \mathrm{x} \in \mathrm{M}_{0}\right\}$. Therefore, we obtain $\mathrm{f}$ $(M) \subset \cup\left\{f\left(U_{x}\right): x \in M_{0}\right\} \subset \cup\left\{V_{\lambda x}: x \in M_{0}\right\}$. Therefore, $f(M)$ is $\delta$ - $\beta$-compact relative to $Y, T^{*}$.

Theorem 3.11: The surjective strongly faint $\delta$ - $\beta$ continuous image of a $\theta$-compact space is $\delta$ - $\beta$-compact. 


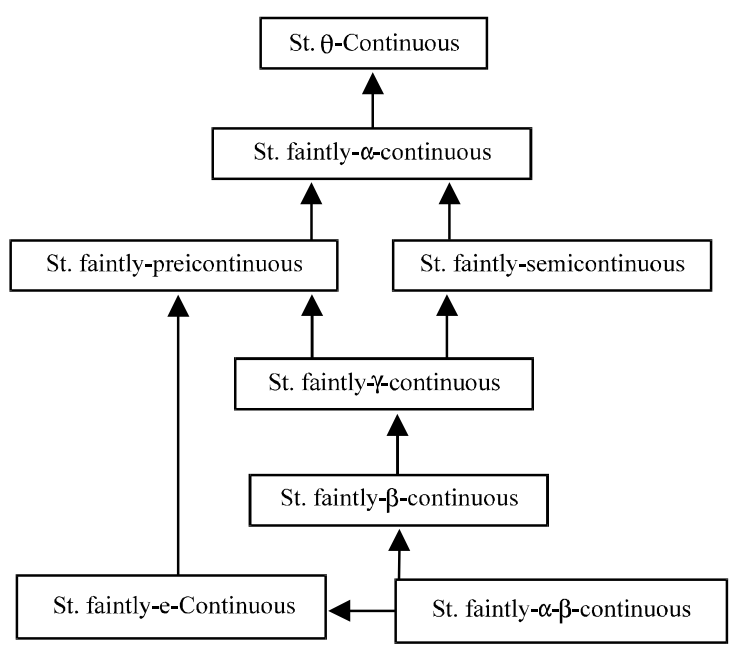

Fig. 2: The relationships between strongly faint $\delta-\beta$ continuous mappings and other of well-known types of strongly faint continuous mappings

Proof: Let $\mathrm{f}:(\mathrm{X}, \mathrm{T}) \rightarrow\left(\mathrm{Y}, \mathrm{T}^{*}\right)$ be a strongly faint $\delta$ - $\beta$-continuous mapping from a $\theta$-compact space $X$ onto a space $Y$. Let $\left\{\mathrm{W}_{\alpha}: \alpha \in \Delta\right\}$ be any $\delta$ - $\beta$-open cover of $Y$. Since, $\mathrm{f}$ is strongly faint $\delta$ - $\beta$-continuous, $\left\{\mathrm{f}^{1}\left(\mathrm{~W}_{\alpha}\right): \alpha \in \Delta\right\}$ is a $\theta$-open cover of $X$. Since, $X$ is $\theta$-compact, there exists a finite subcover $\left\{\mathrm{f}^{1}\left(\mathrm{~W}_{\mathrm{i}}\right): \mathrm{i}=1,2, \ldots, \mathrm{n}\right\}$ of $\mathrm{X}$. Then, it follows that $\left\{\mathrm{W}_{\mathrm{i}} \mathrm{i}=1,2, \ldots, \mathrm{n}\right\}$ is a finite subfamily which cover $\mathrm{Y}$. Hence, $\mathrm{Y}$ is $\boldsymbol{\delta}$ - $\beta$-compact.

Comparisons and examples: In this study, we investigate the relationships between strongly faint $\delta$ - $\beta$-continuous mappings and other well-known types of strong faint continuity.

Definition 4.1: A mapping $\mathrm{f}:(\mathrm{X}, \mathrm{T}) \rightarrow\left(\mathrm{Y}, \mathrm{T}^{*}\right)$ is said to be strongly faint semi-continuous (Nasef, 1998) (resp. strongly faint pre-continuous (Nasef and Noiri, 1996), strongly faint $\gamma$-continuous (Nasef, 1998), strongly faint $\alpha$-continuous (Nasef, 2009), strongly faint $\beta$-continuous (Nasef, 2009), strongly faint e-continuous (Caldas and Jafari, 2011)) if for each $\mathrm{x} \in \mathrm{X}$ and each semiopen (resp. pre-open, $\beta$-open, $\alpha$-open, $\gamma$-open, e-open) set $\mathrm{V}$ of $\mathrm{Y}$ containing $\mathrm{f}(\mathrm{x})$, there exists a $\theta$-open set $\mathrm{U}$ of $X$ containing $\mathrm{x}$ such that $\mathrm{f}(\mathrm{U}) \subset \mathrm{V}$.

Remark 4.2: The relationships between strongly faint $\delta$ - $\beta$-continuous mappings and other corresponding types of mappings are shown in the following diagram.

However, none of these implications is reversible as shown by the example (3.2) of Nasef (1998) (4.3-4.5) of Nasef (2009) and (3.2) of Caldas and Jafari (2011). And the following examples (Fig. 2).
Example 4.3: Using examples (4.3), (resp. Examples: 4.4 and 4.5), of Nasef (2009) these are easily observed that a strongly faint semicontinuity which is not a strongly faint $\delta$ - $\beta$-continuity (resp. a strongly faint precontinuity which is not a strongly faint $\delta$ - $\beta$-continuity and a strongly faint $\gamma$-continuity which is not a strongly faint $\delta$ - $\beta$-continuity).

Example 4.4: Using example (3.2) of Nasef (1998), it is easily observed that a strongly faint $\beta$-continuous which is not a strongly faint $\delta$ - $\beta$-continuity and using example (4.5), (resp. Examples: 4.4) of Nasef (2009) it is easily observed that a strongly faint e-continuous which is not a strongly faint $\delta$ - $\beta$-continuity (resp. a strongly faint precontinuity which is not a strongly faint e-continuity.

A space $X$ is said to be submaximal if each dense subset of $\mathrm{X}$ is open in $\mathrm{X}$ and extremaly disconnected (briefly ED) if the closure of each open set of $\mathrm{X}$ is open in X.

Theorem 4.5: Let $\left(Y, T^{*}\right)$ be a sub-Maximal $E D, T_{e}$-space, and $\mathrm{T}_{8-\beta}$-space, Then the following are equivalent for a mapping $\mathrm{f}:(\mathrm{X}, \mathrm{T}) \rightarrow\left(\mathrm{Y}, \mathrm{T}^{*}\right)$ :

- $\mathrm{f}$ is strongly faint $\alpha$-continuous

- $\mathrm{f}$ is strongly faint $\gamma$-continuous

- $\mathrm{f}$ is strongly faint semi-continuous

- $\mathrm{f}$ is strongly faint pre-continuous

- $\mathrm{f}$ is strongly faint $\beta$-continuous

- $\mathrm{f}$ is strongly $\theta$-continuous

- $\mathrm{f}$ is strongly faint e-Continuous

- $\mathrm{f}$ is strongly faint $\delta$ - $\beta$-continuous

Proof: We have from Nasef (1998), (a) $\Rightarrow(\mathrm{b}) \Rightarrow(\mathrm{c}) \Rightarrow(\mathrm{d}) \Rightarrow$ $(\mathrm{e}) \Rightarrow(\mathrm{f}) \Rightarrow(\mathrm{a})$. (Since, $\mathrm{Y}$ is sub-maximal and $\mathrm{ED}$, then, $\mathrm{T}^{*}=$ $\alpha \Sigma\left(\mathrm{Y}, \mathrm{T}^{*}\right)=\mathrm{B} \Sigma\left(\mathrm{Y}, \mathrm{T}^{*}\right)=\mathrm{S} \Sigma\left(\mathrm{Y}, \mathrm{T}^{*}\right)=\mathrm{P} \Sigma\left(\mathrm{Y}, \mathrm{T}^{*}\right)=\beta \Sigma(\mathrm{Y}$, $\left.\mathrm{T}^{*}\right)$ ). We have from Caldas and Jafari (2011), (f) $\Leftrightarrow(\mathrm{g})$ this follows from the fact that if $\left(\mathrm{Y}, \mathrm{T}^{*}\right)$ is $\mathrm{T}_{\mathrm{e}}$-space, then, $T^{*}=E \Sigma\left(Y, T^{*}\right)$. (f) $\Leftrightarrow(h)$ This follows from the fact that if $\left(Y, T^{*}\right)$ is $T_{\text {a } \cdot \hat{a}}$-space, then $T^{*}=E^{*} \Sigma\left(Y, T^{*}\right) .(g) \oplus(h)$ this is obvious.

Theorem 4.6: If mapping $\mathrm{f}:(\mathrm{X}, \mathrm{T}) \rightarrow\left(\mathrm{Y}, \mathrm{T}^{*}\right)$ is strongly faint $\delta$ - $\beta$-continuous and $\mathrm{g}:\left(\mathrm{Y}, \mathrm{T}^{*}\right) \rightarrow\left(Z, \mathrm{~T}^{* *}\right)$ is $\delta$ - $\beta$-irresolute, then, go $f:(X, T) \rightarrow\left(Z, T^{* *}\right)$ is strongly faint $\delta$ - $\beta$-continuous.

Proof: Let, $\mathrm{W} \in \delta-\beta-\Sigma\left(Z, \mathrm{~T}^{* *}\right)$. Then, we have, $\mathrm{g}^{-1}(\mathrm{~W})$ $\epsilon \delta-\beta-\Sigma\left(\mathrm{Y}, \mathrm{T}^{*}\right)$ and hence, (gof $)^{-1}(\mathrm{~W})=\mathrm{f}^{-1}\left(\mathrm{~g}^{-1}(\mathrm{~W})\right)$ is $\theta$-open in $\mathrm{X}$. Therefore, $\mathrm{g} \circ \mathrm{f}$ is strongly faint $\delta$ - $\beta$-continuous.

Theorem 4.7: For mappings $\left.f:(X, T) \rightarrow Y, T^{*}\right)$ and $g$ : $\left(\mathrm{Y}, \mathrm{T}^{*}\right) \rightarrow\left(\mathrm{Z}, \mathrm{T}^{* *}\right)$ the following statements hold: 
- If both $\mathrm{f}$ and $\mathrm{g}$ are strongly faint $\delta$ - $\beta$-continuous, then the composition $g \circ f: X>Z$ is strongly faint $\delta$ - $\beta$-continuous

- If $\mathrm{f}$ strongly faint $\delta$ - $\beta$-continuous and $\mathrm{g}$ is a $\delta$ - $\beta$-irresolute, then gof is strongly $\delta$ - $\beta$-continuous

- If $\mathrm{f}$ strongly faint $\delta$ - $\beta$-continuous and $\mathrm{g}$ is a $\delta$ - $\beta$-continuous, then gof is strongly $\theta$-continuous

- If $\mathrm{f}$ is quasi $\theta$-continuous and $\mathrm{g}$ is strongly faint $\delta$ - $\beta$-continuous, then, gof is strongly faint $\delta$ - $\beta$ continuous

- If $\mathrm{f}$ is strongly $\theta$-continuous and $\mathrm{g}$ is strongly faint $\delta$ - $\beta$-continuous, then, gof is strongly faint $\delta$ $\beta$-continuous

Proof: The proof is obvious it is follows from their respective definitions

\section{Strongly faint 8 - $\beta$-continuous mappings and separation axioms \\ Definition 5.1: A topological space (X, T) is said to be: $\delta-\beta-\mathrm{T}_{1}$ (Ekici, 2008a-c; Hatir and Noiri, 2009) (resp. 6- $\mathrm{T}_{1}$ (Caldas and Jafari, 2011)) if for each pair of distinct points $\mathrm{x}$ and $\mathrm{y}$ of $\mathrm{X}$, There exists $\delta$ - $\beta$-open (resp. $\theta$-open) sets $\mathrm{U}$ and $\mathrm{V}$ containing $\mathrm{x}$ and $\mathrm{y}$, respectively such that $\mathrm{y} \notin \mathrm{U}$ and $\mathrm{x} \notin \mathrm{V}$. \\ $\delta-\beta-\mathrm{T}_{2}$ (Ekici, 2008a-c; Hatir and Noiri, 2009) (resp. $6-\mathrm{T}_{2}$ (Sinharoy and Bandyopadhyay, 1995) if for each pair of distinct points $\mathrm{x}$ and $\mathrm{y}$ in $\mathrm{X}$, There exists $\mathrm{U} \epsilon \boldsymbol{\delta}-$ $\beta \Sigma(\mathrm{X}, \mathrm{x})$ (resp. $\mathrm{U} \epsilon \Theta \Sigma(\mathrm{X}, \mathrm{x})$ ) and $\mathrm{V} \epsilon \delta-\beta \Sigma(\mathrm{X}, \mathrm{y})$ (resp. $\mathrm{V} \epsilon \theta \Sigma(\mathrm{X}, \mathrm{y})$ such that $\mathrm{U} \cap \mathrm{V}=\varnothing$.}

Remark 5.2: By Caldas et al. (2005) and Nori (1980) Hausdorff space $\Leftrightarrow \theta-T_{1}$ space.

Theorem 5.3: Let, $\mathrm{f}:(\mathrm{X}, \mathrm{T}) \rightarrow\left(\mathrm{Y}, \mathrm{T}^{*}\right)$ be a strongly faint $\delta$ - $\beta$-continuous injection and $Y$ is a $\delta-\beta-T_{1}$ space, then $X$ is a $\theta-\mathrm{T}_{1}$ (or Hausdorff) space.

Proof: Suppose that $Y$ is $\delta-\beta-T_{1}$. For any distinct points $x$ and $y$ in $X$, then there exist $V, H \in \delta-\beta \Sigma\left(Y, T^{*}\right)$ such that $f$ $(x) \in V, f(y) \notin V, f(x) \notin H$ and $f(y) H$. Since, $f$ is strongly faint $\delta$ - $\beta$-continuous, $\mathrm{f}^{-1}(\mathrm{~V})$ and $\mathrm{f}^{-1}(\mathrm{H})$ are $\theta$-open subsets of $\mathrm{X}$, T such that $\mathrm{x} \in \mathrm{f}^{1}(\mathrm{~V}), \mathrm{y} \notin \mathrm{f}^{1}(\mathrm{~V}), \mathrm{x} \notin \mathrm{f}^{1}(\mathrm{H})$ and $\mathrm{y} \in \mathrm{f}^{-1}(\mathrm{H})$. This shows that $X$ is $\theta-T_{1}$ (equivalently Hausdorff by Remark (5.2).

Theorem 5.4: Let $f:(X, T) \rightarrow\left(Y, T^{*}\right)$ be a strongly faint $\delta$ - $\beta$-continuous injection and $Y$ is a $\delta-\beta-T_{2}$ space, then $X$ is a $\theta-\mathrm{T}_{2}$ space.

Proof: Suppose that $\mathrm{Y}$ is $\delta-\beta-\mathrm{T}_{2}$ space. For any pair of distinct points $\mathrm{x}$ and $\mathrm{y}$ in $\mathrm{X}$, there exist disjoint $\delta$ - $\beta$-open sets $U$ and $V$ in $Y$ such that $f(x) \in U$ and $f(y) \in V$. Since, $f$ is strongly faint $\delta$ - $\beta$-continuous, $\mathrm{f}^{-1}(\mathrm{U})$ and $\mathrm{f}^{-1}(\mathrm{~V})$ are $\theta$-open in $\mathrm{X}$ containing $\mathrm{x}$ and $\mathrm{y}$, respectively. Since, $\mathrm{U} \cap \mathrm{V}=\varnothing$. Therefore, $f^{1}(U) \cap f^{-1}(V)=\varnothing$. This shows that $X$ is $\theta-T_{2}$.

Theorem 5.5: If $\mathrm{f}, \mathrm{g}: \mathrm{X}>\mathrm{Y}$ are strongly faint $\delta$ - $\beta$ continuous mappings and $\mathrm{Y}$ is $\delta-\beta-\mathrm{T}_{2}$, then, $\mathrm{K}=$ $\{\mathrm{x} \in \mathrm{X}: \mathrm{f}(\mathrm{x})=\mathrm{g}(\mathrm{x})\}$ is closed in $\mathrm{X}$.

Proof: Suppose that $x \notin K$, then, $f(x) \neq g(x)$. Since, $Y$ is $\delta-\beta-T_{2}$, there exist $V \epsilon \delta-\beta \Sigma(Y, f(x))$ and $H \in \delta-\beta \Sigma(Y, g(x))$ such that $\mathrm{V} \cap \mathrm{H}=\varnothing$. Since, $\mathrm{f}$ and $\mathrm{g}$ are strongly faint $\delta$ - $\beta$-continuous, there exist a $\theta$-open set $U$ of $X$ containing $\mathrm{x}$ and a $\theta$-open set $\mathrm{W}$ of $\mathrm{X}$ containing $\mathrm{x}$ such that $f(U) \subset V$ and $g(W) \subset H$. put $D=U \cap W$. then, $\mathrm{D} \cap \mathrm{K}=\varnothing$ with $\mathrm{D}$ a $\theta$-open subset and hence, open such that $x \in D$. Then, $x \notin C l(K)$ and thus $K$ is closed in $X$.

Definition 5.6: A space (X,T) is said to be $\delta$ - $\beta$-regular if for each $\delta$ - $\beta$-closed set $F$ and each point $x \notin F$, there exist disjoint $\delta$ - $\beta$-open sets $\mathrm{U}$ and $\mathrm{V}$ such that $\mathrm{F} \subset \mathrm{U}$ and $\mathrm{x} \in \mathrm{V}$.

Definition 5.7: A topological space $(X, T)$ is said to be: $\theta$-regular (Caldas et al., 2007) if for each $\theta$-closed set $F$ and each point $\mathrm{x} \notin \mathrm{F}$, there exist disjoint $\theta$-open sets $\mathrm{U}$ and $\mathrm{V}$ such that $\mathrm{F} \subset \mathrm{U}$ and $\mathrm{x} \in \mathrm{V}$. $\theta$-Normal (Caldas et al., 2007) if for any pair of disjoint $\theta$-closed subsets $\mathrm{F}_{1}$ and $\mathrm{F}_{2}$ of $\mathrm{X}$, There exist disjoint $\theta$-open sets $U$ and $V$ such that $F_{1} \subset U$ and $\mathrm{F}_{2} \mathrm{~V}$. $\delta$ - $\beta$-Normal (Ekici 2008a-c) if for any pair of disjoint $\delta$ - $\beta$-closed subsets $F_{1}$ and $F_{2}$ of $X$, There exist disjoint $\delta$ - $\beta$-open sets $U$ \& V such that $F_{1} \subset U$ \& $F_{2} \subset V$. Recall that a mapping f: $(\mathrm{X}, \mathrm{T}) \rightarrow\left(\mathrm{Y}, \mathrm{T}^{*}\right)$ is called $\delta$ - $\beta_{\theta}$-open if $f(U) \in \delta-\beta \Sigma\left(Y, T^{*}\right)$ for each $U \epsilon t_{\theta}$.

Theorem 5.8: Let $\mathrm{f}:(\mathrm{X}, \mathrm{T}) \rightarrow\left(\mathrm{Y}, \mathrm{T}^{*}\right)$ be a strongly faint $\delta$ - $\beta$-continuous $\delta$ - $\beta_{\theta}$-open injection from a $\theta$-regular space $(\mathrm{X}, \mathrm{T})$ onto a space $\left(\mathrm{Y}, \mathrm{T}^{*}\right)$, then $\mathrm{Y}$ is $\delta$ - $\beta$-regular.

Proof: Let, $F$ be a $\delta$ - $\beta$-closed subset of $Y$ and $y \notin F$. Take $y=f(x)$. Since, $f$ is strongly faint $\delta$ - $\beta$-continuous, $\mathrm{f}^{1}(F)$ is $\theta$-closed in $X$ such that $\mathrm{f}^{1}(\mathrm{y})=\mathrm{x} \oplus \mathrm{f}^{-1}(F)$. Take $\mathrm{W}=\mathrm{f}^{1}(F)$. We have $x \notin W$. Since, $X$ is $\theta$-regular, then there exist disjoint $\theta$-open sets $U$ and $V$ in $X$ such that $\mathrm{W} \subset \mathrm{U}$ and $x \in V$. We obtain that $F=f(W) \subset f(U)$ and $y=f(x) \in f(V)$ such that $f(U)$ and $f(V)$ are disjoint $\delta$ - $\beta$-open sets. This shows that $Y$ is $\delta$ - $\beta$-regular.

Theorem 5.9: Let, $\mathrm{f}:(\mathrm{X}, \mathrm{T}) \rightarrow\left(\mathrm{Y}, \mathrm{T}^{*}\right)$ be a strongly faint $\delta$ - $\beta$-continuous $\delta$ - $\beta_{\theta}$-open injection from a $\theta$-normal space $(\mathrm{X}, \mathrm{T})$ onto a space $\left(\mathrm{Y}, \mathrm{T}^{*}\right)$, then $\mathrm{Y}$ is $\delta$ - $\beta$-normal.

Proof: Let $F_{1}$ and $F_{2}$ be disjoint $\delta$ - $\beta$-closed subsets of $Y$. 
Since, $\mathrm{f}$ is strongly faint $\delta$ - $\beta$-continuous, $\mathrm{f}^{-1}\left(\mathrm{~F}_{1}\right)$ and $\mathrm{f}^{-1}\left(\mathrm{~F}_{2}\right)$ are $\theta$-closed sets. Take $U=\mathrm{f}^{1}\left(\mathrm{~F}_{1}\right)$ and $\mathrm{V}=\mathrm{f}^{-1}\left(\mathrm{~F}_{2}\right)$. We have $\mathrm{U} \cap \mathrm{V}=\varnothing$. Since, $\mathrm{X}$ is $\theta$-normal, there exist disjoint $\theta$ open sets $\mathrm{A}$ and $\mathrm{B}$ such that $\mathrm{U} \subset \mathrm{A}$ and $\mathrm{V} \subset \mathrm{B}$. We obtain that $F_{1}=f(U) \subset f(A)$ and $F_{2}=f(V) \subset f(B)$ such that $f(A)$ and $\mathrm{f}(\mathrm{B})$ are disjoint $\delta$ - $\beta$-open sets. Thus, $\mathrm{Y}$ is $\delta$ - $\beta$-normal. Recall that for a mapping $\mathrm{f}:(\mathrm{X}, \mathrm{T}) \rightarrow\left(\mathrm{Y}, \mathrm{T}^{*}\right)$, the subset $\{(x, f(x)): x \in X\} \subset X \times Y$ is called the graph of $f$ and is denoted by $G(f)$.

Definition 5.10: A graph $G(f)$ of a mapping $f$ : ( $X$, $T) \rightarrow\left(Y, T^{*}\right)$ is said to be $\delta$ - $\beta_{\theta}$-closed if for each $(x$, y) $\epsilon(X \times Y) \backslash G(f)$, there exist a $\theta$-open $U$ set of $X$ containing $\mathrm{x}$ and $\delta$ - $\beta$-open set $\mathrm{V}$ of $\mathrm{Y}$ containing y such that $(\mathrm{U} \times \mathrm{V}) \cap \mathrm{G}$ $(\mathrm{f})=\varnothing$.

Lemma 5.11: A graph $G(f)$ of a mapping $f:(X, T) \rightarrow\left(Y, T^{*}\right)$ is $\delta$ - $\beta_{\theta}$-closed in $X \times Y$ if and only if for each ( $x$, y) $\epsilon(X \times Y) \backslash G(f)$, there exist a $\theta$-open set $U$ of $X$ containing $\mathrm{x}$ and an $\delta$ - $\beta$-open set $\mathrm{V}$ of $\mathrm{Y}$ containing $\mathrm{y}$ such that $\mathrm{f}(\mathrm{U}) \cap \mathrm{V}=\varnothing$.

Proof: It is follows immediately from Definition (5.10).

Theorem 5.12: Let $f: X>Y$ be a strongly faint $\delta$ - $\beta$-continuous mapping and $\left(Y, T^{*}\right)$ is $\delta$ - $\beta-T_{2}$, then $G(f)$ is $\delta$ - $\beta_{\theta^{-}}$-closed.

Proof: Let $(x, y) \rightarrow(X \times Y) \backslash G(f)$, then $f(x) \neq y$. Since, $Y$ is $\delta$ - $\beta-T_{2}$, there exist disjoint $\delta$ - $\beta$-open sets $\mathrm{V}$ and $\mathrm{H}$ in $Y$ such that $f(x) \in V$ and $y \in H$. Since, $f$ is strongly faint $\delta$ - $\beta$-continuous, then $\mathrm{f}^{-1}(\mathrm{~V})$ is $\theta$-open in $\mathrm{X}$ containing $\mathrm{x}$. Take $U=f^{1}(V)$. We have $f(U) \subset V$. Therefore, we obtain $f$ $(\mathrm{U}) \cap \mathrm{H}=\varnothing$. This shows that $\mathrm{G}(\mathrm{f})$ is $\delta$ - $\beta_{\theta}$-closed.

Theorem 5.13: Let $f: X>Y$ be a strongly faint $\delta-\beta-$ continuous injection and has an $\delta-\beta_{\theta}$-closed graph, then $(\mathrm{X}, \mathrm{T})$ is $\theta-\mathrm{T}_{2}$.

Proof: Let, $\mathrm{x}$ and $\mathrm{y}$ be any two distinct points of $\mathrm{X}$. Then since, $f$ is injective, we have $f(x) \neq f(y)$. Then, we have $(x, f$ (y)) $\epsilon(X \times Y) \backslash G(f)$. By Lemma (5.11), there exist a $\theta$-open set $\mathrm{U}$ of $\mathrm{X}$ and a $\delta$ - $\beta$-open set $\mathrm{V}$ of $\mathrm{Y}$ such that $(\mathrm{x}, \mathrm{f}(\mathrm{y})) \in \mathrm{U} \times \mathrm{V}$ and $f(U) \cap V=\varnothing$. Hence, $U \cap f^{-1}(V)=\varnothing$ and $y \notin U$. Since, $f$ is strongly faint $\delta$ - $\beta$-continuous, there exists a $\theta$-open set $\mathrm{H}$ of $\mathrm{X}$ containing y such that $\mathrm{f}(\mathrm{H}) \subset \mathrm{V}$. Therefore, we have $f(U) \cap f(H)=\varnothing$. Since, $f$ is injective, we obtain $U \cap H=$ $\varnothing$. This implies that $(\mathrm{X}, \mathrm{T})$ is $\theta-\mathrm{T}_{2}$.

Definition 5.14: A topological space $X$ is said to be $\delta$ - $\beta$-Alexandroff if every finite intersection of $\delta$ - $\beta$-open sets is $\delta$ - $\beta$-open.

Theorem 5.15: Let $\mathrm{f}:(\mathrm{X}, \mathrm{T}) \rightarrow\left(\mathrm{Y}, \mathrm{T}^{*}\right)$ has a $\delta$ - $\beta_{\theta}$-closed graph and Let $\left(Y, T^{*}\right)$ be $\delta$ - $\beta$-Alexandroff, then $f(M)$ is $\delta$ - $\beta$-closed in $Y, T^{*}$ for each subset $M$ which is $\theta$ compact relative to $\mathrm{X}$.

Proof: Suppose that $y \notin f(M)$. Then $(x, y) \notin G(f)$ for each $x \in M$. Since, $G(f)$ is $\delta$ - $\beta_{\theta}$-closed, there exist a $\theta$-open set $U_{x}$ of $\mathrm{X}$ containing $\mathrm{x}$ and $\delta$ - $\beta$-open set $\mathrm{V}_{\mathrm{x}}$ of $\mathrm{Y}$ containing $y$ such that $f\left(U_{\mathrm{z}}\right) \mathrm{nV}_{\mathrm{z}}=\varnothing$, By Lemma (5.11). The family $\left\{U_{x}: x \in M\right\}$ is a cover of $M$ by $\theta$-open sets. Since, $M$ is $\theta$-compact relative to $\mathrm{X}, \mathrm{T}$, there exists a finite subset $\mathrm{M}_{0}$ of $\mathrm{M}$ such that $\mathrm{M} \subset \cup\left\{\mathrm{U}_{\mathrm{x}}: \mathrm{x} \in \mathrm{M}_{0}\right\}$. Put $\mathrm{V}=\cap\left\{\mathrm{V}_{\mathrm{x}}: \mathrm{x} \in \mathrm{M}_{0}\right\}$. Then, $\mathrm{V}$ is an $\boldsymbol{\delta}$ - $\beta$-open set in $\mathrm{Y}$ containing y. Therefore, we have:

$$
\mathrm{f}(\mathrm{M}) \cap \mathrm{V} \subset\left[\bigcup_{\mathrm{x} \in \mathbb{M}_{0}} \mathrm{f}\left(\mathrm{U}_{\mathrm{z}}\right)\right] \subset \bigcup_{\mathrm{x} \in \mathbb{M}_{0}}\left[\mathrm{f}\left(\mathrm{U}_{\mathrm{z}}\right) \cap \mathrm{V}\right]=\varnothing
$$

It follows that $\mathrm{y} \notin \delta-\beta-C l(f(M))$. Therefore, $f(M)$ is $\delta$ - $\beta$-closed in $\left(Y, T^{*}\right)$.

Corollary 5.16: Let $\left(Y, T^{*}\right)$ be $\delta$ - $\beta$-Alexandroff. If $\mathrm{f}$ : $(\mathrm{X}, \mathrm{T}) \rightarrow\left(\mathrm{Y}, \mathrm{T}^{*}\right)$ is strongly faint $\delta$ - $\beta$-continuous and $\left(\mathrm{Y}, \mathrm{T}^{*}\right)$ is $\delta-\beta-T_{2}$, then, $f(M)$ is $\delta$ - $\beta$-closed in $Y, T^{*}$ for each subset $\mathrm{M}$ which is $\theta$-compact relative to $\mathrm{X}, \mathrm{T}$.

Proof: The proof follows from Theorems (5.12) and (5.15).

\section{CONCLUSION}

The notion of continuity is significant and fundamental subject in the study of general topology as well as all branches of mathematics and quantum Physics has been researched and investigated by several mathematicians and quantum physicists. Caldas et al. (2005, 2007), Ekici (2007a, b), El-Naschie (2004a, b, 2006), Noiri and Popa (2004), Park and Park (2004) and Park et al. (2006) from the different points of views, of course its weak forms and strong forms are important, too. Many investigations related to closed sets have been published and various forms of continuity types have been introduced. For instance, some strong forms of closed sets such as regular closed sets and some weak forms such as semi-closed, pre-closed, $\delta$ - $\beta$-closed sets were investigated. Topology as a field of mathematics is concerned with all questions directly or indirectly related to continuity. Therefore, the theory of faint continuity is one of the most significant subjects in topology. Thus we study a new class of strong form of faint continuity which may have very important applications in high energy Physics, quantum particle Physics and superstring theory. In addition, there was a contribution towards the 
resolution of some fundamental questions linking space time geometry and topology to high-energy particle Physics. Thus, it should be mentioned that the present research may become relevant to the researches of (El-Naschie, 1998, 2000, 2002, 2004a, b, 2006). On the other hand, the mathematical theory of fuzzy sets is highly developed and used extensively in many practical and engineering problems. Fractal geometry is by its very nature, fuzzy and that is how K3 which is used in String theory for other purposes could be given, a fuzzy outlook. Furthermore, fuzzy topological version of the notions and results introduced in this study are very important, since, El-Naschie has shown that the notion of fuzzy topology have very important applications in quantum particle Physics, especially, in related to both String theory and $\varepsilon^{\circ}$ theory (El-Naschie, 1998, 2004a, b).

\section{REFERENCES}

Caldas, M. and S. Jafari, 2011. On strongly faint E-continuous functions. Proyecciones Antofagasta, 30: $29-41$.

Caldas, M., S. Jafari and T. Noiri, 2011. Some separation axioms via. modified $\theta$-open sets. Bull. Iran. Math. Soc., 29: 1-12.

Caldas, M., S. Jafari, T. Noiri and M. Simoes, 2007. A new generalization of contra-continuity via Levines g-closed sets. Chaos, Solitons Fractals, 32: 1597-1603.

Caldas, M., S. Jafari, T. Noiri and R.K. Saraf, 2005. Weak and strong forms of a-irresolute maps. Chaos, Solitons Fractals, 24: 223-228.

EL-Naschie, M.S., 2004c. Topological defects in the symplictic vacuum, anomalous positron production and the gravitational instanton. Intl. J. Modern Phys. E., 13: 835-849.

Ekici, E., 2007b. On almost pgp-continuous functions. Chaos Solitons Fractals, 32: 1935-1944.

Ekici, E., 2007a. Some generalizatons of almost contra-super-continuity. Filomat, 21: 31-44.

Ekici, E., 2008b. A note on $\alpha$-open sets and $\mathrm{e}^{*}$-open sets. Filomat, 22: 89-96.

Ekici, E., 2008a. New forms of contra-continuity. Carpathian J. Math., 24: 37-45.

Ekici, E., 2008c. On E-open sets, DP*-sets and DPE*-sets and decompositions of continuity. Arabian J. Sci. Eng., 33: 269-282.

Ekici, E., 2009. On e*-open sets and $(\mathrm{D}, \mathrm{S})^{*}$-sets. Math. Moravica, 13: 29-36.

E1 Naschie, M.S., 1988. On the uncertainty of cantorian geometry and the two-slit experiment. Chaos Solitons Fractals, 9: 517-529.

El Naschie, M.S., 2000. On the unification of heterotic strings, $\mathrm{M}$ theory and $\mathrm{E}(8)$ theory. Chaos Solitons
Fractals, 11: 2397-2408.

El Naschie, M.S., 2002. Wild topology, hyperbolic geometry and fusion algebra of high energy particle physics. Chaos Solitons Fractals, 13: 1935-1945.

E1 Naschie, M.S., 2004a. A review of E infinity theory and the mass spectrum of high energy particle physics. Chaos Solitons Fractals, 19: 209-236.

El Naschie, M.S., 2004b. Quantum gravity, clifford algebras, fuzzy set theory and the fundamental constants of nature. Chaos Solitons Fractals, 20: 437-450.

El Naschie, M.S., 2006. Topics in the mathematical physics of E-infinity theory. Chaos Solitons Fractals, 30: 656-663.

El-Atik, A.A., 1997. A study of some types of mappings on topological spaces. Masters Thesis, Tanta University, Tanta, Egypt.

El-Monsef, M.E.A., S.N. Eldeeb and R.A. Mahmoud, 1983. $\mathrm{B}$-open sets and $\beta$-continuous mappings. Bull. Fac. Sci. Assiut. Chiv. A, 12: 77-90.

Farhan, A.M. and X.S. Yang, 2015. New type of strongly continuous functions in topological spaces via. $\delta$ - $\beta$-open sets. Eur. J. Pure Appl. Math., 8: 185-200.

Hatir, E. and T. Noiri, 2006. Decompositions of continuity and complete continuity. Acta Math. Hungarica, 113: 281-287.

Hatir, E. and T. Noiri, 2009. On $\delta$ - $\beta$-continuous functions. Chaos Solitons Fractals, 42: 205-211.

Jafari, S., 1998. Some properties of quasi-continuous functions. Far East J. Math. Sci., 6: 689-696.

Levine, N., 1970. Generalized closed sets in topology. Rend. Circ. Mat. Palermo, 19: 89-96.

Levine, N., 1963. Semi-open sets and semi-continuity in topological spaces. Am. Math. Mon., 70: 36-41.

Long, P.E. and L. Herrington, 1982. The T6-topology and faintly continuous functions. Kyungpook Math. J., 22: 7-14.

Mashhour, A.S., M.A. El-Monsef and S.N. El-Deeb, 1982. On precontinuous and weak precontinuous mappings. Proc. Math. Phys. Soc. Egypt, 53: $47-53$.

Nasef, A.A. and T. Noiri, 1996. Strongly-irresolute functions. J. Nat. Sci. Math. Lahore, 36: 199-200.

Nasef, A.A., 1998. Strong forms of faint continuity. Mem. Fac. Sci. Kochi Univ. Ser. A Math., 19: 21-28.

Nasef, A.A., 2009. Recent progress in the theory of faint continuity. Math. Comput. Modell., 49: 536-541.

Njastad, O., 1965. On some classes of nearly open sets. Pac. J. Math., 15: 961-970.

Noiri, T. and V. Popa, 2004. Faintly M-continuous 
functions. Chaos Solitons Fractals, 19: 1147-1159.

Noiri, T., 1980. On d-continuous functions. J. Korean Math. Soc., 16: 161-166.

Park, J.H, S.W. Bae and Y.B. Park, 2006. Almost strongly $\theta$-pre-continuous functions. Chaos Solitons Fractals., 28: $32-41$.

Park, J.H. and J.K. Park, 2004. On pgp-continuous functions in topological spaces. Chaos Solitons Fractals, 20: 467-477.
Raychaudhuri, S. and M.N. Mukherjee, 1993. On d-almost continuity and d-preopen sets. Bull. Inst. Math. Acad. Sinica., 21: 357-366.

Sinharoy, S. and S. Bandyopadhyay, 1995. On $\theta$-completely regular and locally $\theta-\mathrm{H}$-closed spaces. Bull. Cal. Math. Soc., 87: 19-26.

Velicko, N.V., 1968. H-closed topological spaces. Amer. Math. Soc. Transl., 78: 103-118. 